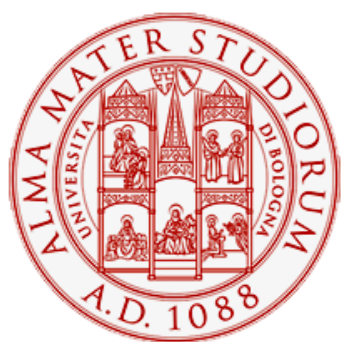

Alma Mater Studiorum - Università di Bologna DEPARTMENT OF ECONOMICS

Tobacco Taxes and Smoking Bans Impact Differently on Obesity and Eating Habits

Davide Dragone

Francesco Manaresi

Luca Savorelli

Quaderni - Working Paper DSE N878

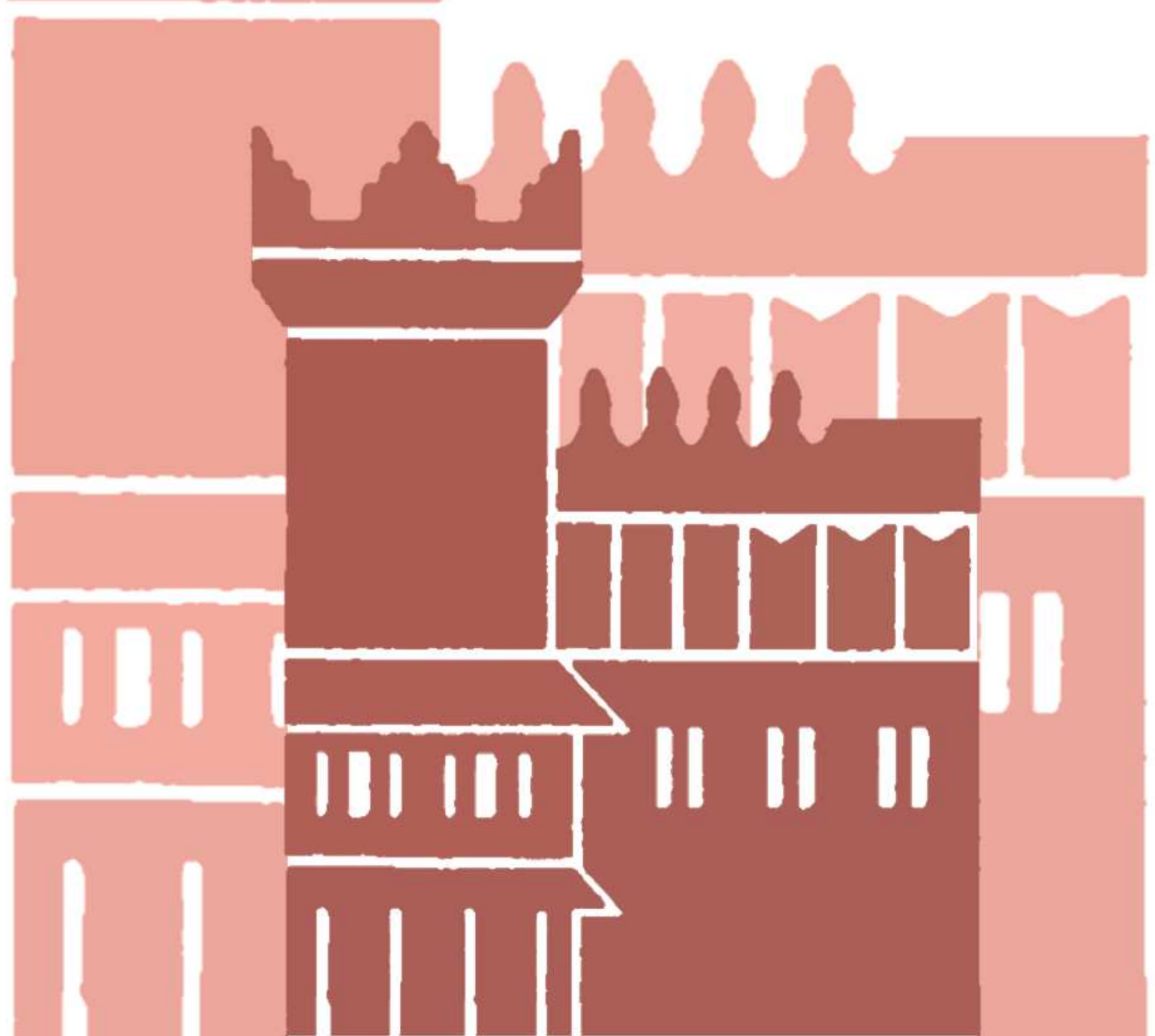




\title{
Tobacco Taxes and Smoking Bans Impact Differently on Obesity and Eating Habits*
}

\author{
Davide Dragone ${ }^{\S} \quad$ Francesco Manaresi ^ Luca Savorellill
}

April 23, 2013

\begin{abstract}
Policy interventions aimed at affecting a specific behavior may also indirectly affect individual choices in other domains. In this paper we study the direct effect of tobacco excise taxes and smoking bans on smoking behavior, and the indirect effect on eating behavior and body weight. Using very detailed clinical data on individual health, smoking, and dietary habits, we show that antismoking policies are effective in reducing smoking, but their consequences on eating behavior dramatically depend on the specific implemented policy. Increasing excise taxes on tobacco decreases body weight and caloric intake, and it improves the quality of eaten food. Smoking bans, instead, do not significantly affect body weight, although they impact on the diet composition. Smoking bans in restaurants induce a significant rise in the quality of food and in daily caloric intake. Conversely, smoking bans in bars negatively affect the quality of the daily diet, as individuals eat more fats and less fibers, and drink more alcohol and caffeine.
\end{abstract}

Keywords: Ban, Diet, Obesity, Policy Evaluation, Smoking.

JEL-Code: I10, I18.

*We thank Jérôme Adda, Francesca Cornaglia, Simonetta Salvini, and the participants to the AIES 2011 conference and to the seminars at the University of Bologna for useful discussions and feedback. We also thank Jonathan Gruber for kindly sharing some data for the empirical analysis. Financial support from the SoNIC project (FIRB grant no. RBFR084L83) and from the FarmaFactoring Foundation is gratefully acknowledged. The views expressed in this paper are the authors' own and do not necessarily reflect those of the Bank of Italy. The usual disclaimer applies. 


\section{Introduction}

Smoking and obesity are major sources of public health concern as they are, respectively, the first and the second leading cause of preventable death in the US (Flegal et al., 2005, Mokdad et al., 2004). Government interventions to reduce smoking and obesity have been typically justified on the basis of the argument that smoking and obesity produce externalities (Chaloupka, Warner, 1998, Evans et al., 1999, Gruber, 2001, Finkelstein et al., 2004) or, in case of dynamically inconsistent preferences, internalities (Gruber and Köszegi, 2001, 2004) which the policy maker should correct. Antismoking policies have included the introduction of tobacco excise taxes and smoking bans, educational interventions, advertising campaigns, and the provision of assistance and tutoring. In this paper we focus on excises and smoking bans, which aim at discouraging smoking behavior by directly raising the cost of smoking tobacco. The established literature shares the view that these policies are very effective in reducing tobacco consumption by smokers. ${ }^{1}$ The suggestive evidence that, over the last thirty years, smoking prevalence has been decreasing while obesity prevalence has been increasing, has raised the question of whether antismoking policies have also had unintended effects on individual behavior and, in particular, whether they have increased food consumption and individual weight. This conjecture is consistent with the medical evidence that nicotine intake reduces appetite and accelerates indi-

\footnotetext{
${ }^{\S}$ Corresponding author: Davide Dragone, University of Bologna, Dipartimento di Scienze Economiche, Piazza Scaravilli 1, 40126 Bologna, Italy; Phone: +39-051-209-8880, Fax: +39-051-209-8143, E-mail: davide.dragone@unibo.it.

"Bank of Italy, Structural Economic Analysis - Labour Market Division, via Nazionale 91, 00184 Rome, Italy; Phone:+39-06-479-224-26; E-mail: francesco.manaresi@bancaditalia.it.

"University of St Andrews, School of Economics \& Finance, Castlecliffe, The Scores, St. Andrews, Fife KY16 9AR, Scotland, United Kingdom. Tel. +44-1334-46-2449; E-mail: luca.savorelli@st-andrews.ac.uk.

${ }^{1}$ For example, Sweanor and Martial (1994) show that in Canada a $500 \%$ increase in excise taxes has caused a $38 \%$ drop in smoking rate in the period $1982-1992$, and Liu et al. (2010) find that in the US the introduction of smoking bans in working places has reduced smoking rates by 31\% during the period 1998 - 2006. Adda and Cornaglia (2006) argue that the reduction in the number of cigarettes smoked is counter-balanced by the increase in smoking intensity (i.e., in the cotinine content of each cigarette smoked). Their finding has been criticised by Abrevaya and Puzzello (2012). See Adda and Cornaglia (2011) for a response to the critique.
} 
vidual metabolism (Chiolero et al., 2008, Mineur et al., 2011), and with the popular wisdom that quitters gain body weight. ${ }^{2}$

To assess the effects of tobacco excise taxes and smoking bans on eating behaviors and body weight, we exploit the geographical and temporal variability in the implementation of US antismoking policies. Our analysis is based on the 1999-2008 waves of the National Health And Nutrition Examination Survey (henceforth, NHANES), a cross-sectional representative survey of the US population that combines interviews, daily food diaries, medical examinations and blood tests, in addition to a set of motivational questions about dieting and exercising. The level of detail of this dataset allows to draw a reliable picture of individual eating habits and to clearly identify the channels through which antismoking policies affect individual behavior and health.

Our results show that rising the taxes on cigarettes has a positive effect on all proxies of a healthy diet. The share of fats over total nutrients is reduced and the share of fibers and carbohydrates increases. Moreover, after two years since the increase of the excises, individuals display a lower concentration of LDL cholesterol and triglycerides in blood. These findings are confirmed by additional self-reported information on eating habits showing that, after two years since the raise in excise tax, individuals are more likely to control their weight and choose to eat less. Consistently with the recent findings of Courtemanche (2009) and Wehby and Courtemanche (2012), we find that a 10-cent increase in tobacco excise taxes reduces average BMI by $2.5 \%$ over a two-year horizon, an effect which our dataset allows to link to a quantitative reduction in terms of both a lower amount of total nutrients ingested and a lower daily caloric intake.

The effects of smoking bans are markedly different from the effects of taxes on tobacco, and they crucially depend on the type of public place in which the ban is enacted. In general, bans have no effect on BMI, however they do affect the quantity and quality of food eaten. After two years since the enactment of bans in bars, daily total nutrients intake decreases and the

\footnotetext{
${ }^{2}$ Adda and Cornaglia (2010) consider another possible unintended consequence: they provide evidence that smoking banks in public places have induced people to smoke more at home, which has negatively affected the health of their live-in partners (notably, their children) via secondary smoking.
} 
quality of food gets worse, with a larger share of fats at the expenses of carbohydrates and fibers. Conversely, bans in restaurants raise daily caloric intakes and total eaten nutrients. Interestingly, bans in bars and restaurants have opposite effects on cholesterol in blood: the former policy rises HDL cholesterol (the "good" cholesterol) and reduces LDL cholesterol (the "bad" cholesterol), while the latter increases LDL Cholesterol. This has relevant health consequences, because a higher concentration of HDL cholesterol in blood can induce atherosclerosis, an important risk factor for many heart diseases. LDL cholesterol, instead, is generally found to reduce the risk of heart attacks.

Our results confirm that, although antismoking polices were targeted to smoking behavior, they had an additional (and possibly unintended) impact on individual behavior and health. This may be an issue for the design of health-related policies, as they are often discussed and carried over under the implicit assumption that health-related behaviors are independent and that no relevant interconnection exists among them. When considering smoking and eating behavior, which are the two main causes of preventable death in most industrialized countries, this assumption does not seem to hold. Moreover, the direction of these effects can significantly vary in magnitude and sign, depending on the specific implemented antismoking policy.

The negative correlation between obesity and smoking prevalence has motivated a number of economic papers to study the effect of increasing cigarette taxes and prices on body weight. In line with the common wisdom and the medical evidence that cigarettes help reducing body weight, some studies find that a raise in cigarette prices (or excises) on average increases BMI (Chou et al., 2004; Rashad and Grossman, 2004; Rashad et al., 2006; Baum, 2009). Other papers point to the opposite direction, finding that an increase in cigarette prices decreases BMI (Gruber and Frakes, 2006; Courtemanche, 2009; Wehby and Courtemanche, 2012). Courtemanche (2009) shows that this mixed evidence can be reconciled if lags for cigarette prices or taxes are included in the analysis. When lags are considered, all methodologies lead to the conclusion that cigarette price is negatively associated with BMI and obesity. We improve on this literature in three directions.

First, we provide new evidence on the mechanisms that drive the negative 
effect of excise taxes on weight. These mechanisms are still under scrutiny and the related evidence is scarce. Using self-reported answers contained in the BRFSS dataset, Wehby and Courtemanche (2012) and Courtemanche (2009) suggest that the negative effect of prices is driven by increased exercising and an improved attitude towards health. Since self-reported measures are likely to be imprecise, these authors suggested that following research should employ a broader range of data. Using clinical data from NHANES, we show that most of the reduction in body weight is consciously pursued by individuals through a stricter diet, and that more attention paid to the quality of food eaten.

Second, we extend the analysis beyond BMI, including a full set of objective dietary variables. Indeed, BMI is a highly synthetic, but rather crude measure of the body weight condition. It conveys no qualitative or quantitative information on food intake and it does not allow to distinguish fat from lean mass (Burkhauser and Cawley, 2008, Prentice and Jebb, 2001). A more precise identification of the effect of anti-smoking policies on individual eating behavior may allow the researcher to better understand the channels through which smoking, eating, and body weight are related. In addition, studying the effect on the quality of food eaten allows a more precise assessment of the potential unintended health benefits or costs of these policies.

Third, we broaden the analysis to smoking bans in bars, restaurants, and workplaces. These policies have been only marginally analysed by previous studies. Chou et al. (2004) include clean indoor air laws in their regressions and find no consistent pattern (insignificant effects for bans in restaurants and working places, and a significant positive effect on BMI only for a residual category including places such as elevators and public transport). Liu et al. (2010) study the effect of smoking bans in workplaces and find a positive impact on BMI. However, their paper focuses on a single type of anti-smoking policy: as we will discuss in Section 3, the introduction of these policies have been often almost simultaneous, and thus their specific effect can be identified only by including all of them in the same econometric model. Consistently with Chou et al. (2004) we show that BMI is not significantly affected by smoking bans. However, other relevant dimensions of eating behavior, notably the quantity of food eaten and its quality, are in- 
deed influenced. The assessment of the qualitative and quantitative changes in the diet composition allows for understanding the mechanisms through which each antismoking policy affects individual behavior and health. This may provide useful information for the policy maker which aims at choosing the most appropriate intervention for improving population health.

The remainder of the paper is structured as follows. Section 2 discusses the identification strategy that we implement to estimate the causal effect of anti-smoking policies, while Section 3 introduces the data used for the empirical analysis. Section 4 presents the results, and Section 5 discusses them. Section 6 concludes.

\section{Empirical Strategy}

We want to study the effect of anti-smoking policies on several proxies of the quantity and quality of food consumed. Courtemanche (2009) argues that the effect of tobacco excise taxes on BMI may be appreciated only in the mediumlong term. This is because changes in cigarette smoking may lag excise tax changes, changes in food consumption may lag cigarette smoking, and finally BMI is likely to lag food consumption, as body-mass is a stock variable that is accumulated over time. The same reasoning applies to smoking bans. In addition, in this case, pricing strategies by bars and restaurants may lag the introduction of bans, and the potential peer effect produced by antismoking policies may take some time to become effective. For these reasons, we consider both one-year and two-year lags in the effective coverage of each policy. We thus estimate the following empirical model:

$$
\begin{aligned}
D V_{i s t}=\alpha & +\sum_{h=0}^{1} \beta_{h} \overline{\operatorname{Tax}}_{s, t-365 h}+\sum_{h=0}^{1} \gamma_{h} \overline{\operatorname{Tax}}_{s, t-365 h}^{2}+\sum_{h=0}^{1} \delta_{h} \overline{\operatorname{Bar}}_{s, t-365 h}+\sum_{h=0}^{1} \lambda_{h} \overline{\operatorname{Rest}}_{s, t-365 h} \\
& +\sum_{h=0}^{1} \mu_{h} \overline{\operatorname{Work}}_{s, t-365 h}+X \psi+\text { State }_{s}+\text { Month }_{t} \times \text { Year }_{t}+\text { State }_{s} \times t+\varepsilon_{i s t}
\end{aligned}
$$

where $i$ indexes a sampled individual, $s$ is her state of residence, and $t$ is the day in which she was interviewed by NHANES ( $t \in\{$ January 1 1999, . ., December 312008$\}$ ). 
$D V_{i s t}$ is one of the dependent variables discussed below. $\overline{\operatorname{Tax}}_{s, t}$ is the average tobacco excise tax experienced in state $s$ during the first year before day $t$, and $\overline{\operatorname{Tax}}_{s, t-365}$ is the average tobacco excise tax experienced in state $s$ during the second year before day $t$. Similarly, $\overline{\operatorname{Bar}}_{s, t}, \overline{\operatorname{Rest}}_{s, t}$ and $\overline{\text { Work }}_{s, t}$ are the average effective strengths of bans experienced in the year before date $t$ in, respectively, bars, restaurants, and working places. $X$ is a vector of individual and household characteristics. ${ }^{3}$ We control for state-level unobserved heterogeneity by including a state fixed effect, and for any collective shock at the US level by including a month-times-year fixed effect. ${ }^{4}$ Finally, we include a state-specific time trend in the regressions, to control for possible state-specific unobservable characteristics (e.g., health consciousness) that may affect the trends of both individual health and the enactment of anti-smoking policies.

\section{Data and descriptive statistics}

The main data source for our analysis is the 1999-2008 NHANES, administered by the Center for Disease Control (CDC). The NHANES is a biannual representative survey of the US population. Every two years, around 10,000 individuals of all ages are interviewed and physically examined. The main advantage of NHANES with respect to other health-related surveys (such as the Behavioral Risk Factor Surveillance System) is the rich set of information it collects from each interviewed person. ${ }^{5}$ The NHANES interviews collect demographic, socioeconomic, dietary and health-related questions, while the examinations include anthropometric measurements and blood tests administered by medical personnel. In addition, interviewed individuals must complete a daily food diary, which is then combined with nutritional data

\footnotetext{
${ }^{3}$ Individual characteristics include gender of the individual, a second order polynomial in age, education (measured with a dummy $=1$ if the individual has at least some college education), ethnicity, and the day of the week in which the interview took place. Household controls include gender, age, squared age, and education of the household head, household size, and household poverty as measured by the distance between household disposable income per adult-equivalent and the poverty line.

${ }^{4}$ In principle, one could use sharper controls, such as week-times-year of day-ofinterview fixed effects. However, sample size prevents us from identifying such effects.

${ }^{5}$ Conversely, the BRFSS has a larger sample size and a panel dimension.
} 
to obtain very detailed information on eating habits. For each interviewed person, we obtained restricted information on the state of residence and on the date of interview. We use both these sources of information to attribute the average tobacco excise tax and the average strength of the smoking bans in bars, restaurants, and workplaces faced by individuals in the two years before the interview (see Section 2).

We restrict our attention to the adult population (aged 21 or more) and we use the sampling weights provided by CDC to obtain representative estimates for the US population. Table 1 reports descriptive statistics of all the variables used in the main empirical analysis. We focus on a stock measure of food consumption (BMI), and two flow measures (daily caloric intake and daily nutritional intake). In addition, food diaries and blood analyses allow us to study the effect of antismoking policies on measures of the quality of the diet, such as the share of different nutrients (proteins, carbohydrates, fibers, and fats), alcohol and caffeine consumption, and blood levels of HDL and LDL cholesterol and triglycerides.

The negative correlation between smoking and BMI (often found in the medical literature) can be appreciated in Table 2. Indeed, smokers are overrepresented among underweight individuals, and under-represented among overweight and obese. Obviously, this spurious correlation cannot be used to infer any causal relationship.

Data on tobacco excise taxes at the state level come from the Tax Burden on Tobacco by Orzechowski and Walker (2011). The publication reports the exact enactment date of each modification in excise taxes issued by US state Governments.

Information on smoking bans are obtained from the American Non-smokers' Rights Foundation (ANRF). The ANRF collects information on the enactment date of each clean outdoor air law issued at the city, county, or state level since the early 1920s. Three types of bans are observed: antismoking bans in bars, in restaurants, and in workplaces. The strength of any law takes a discrete value ranging from 0 (no bans) to 3 (complete ban). Simply using state-level laws would underestimate the effective strength of the bans perceived by state population. This is because in many states there are several local laws that are much stronger than the state law. Counties and 
cities can only impose stronger bans with respect to those provided by state law. To take this into consideration, we tessellate each state into administrative territories, that are either cities or unincorporated areas; we attribute to each of these administrative territories the maximum strength of the ban among those envisaged at the territory level $a$, county level $c$ and state level $s$. Finally, for each state and each day $t$ of the period 1997-2008, we construct three variables $\left(\operatorname{Bar}_{s, t}\right.$, Rest ${ }_{s, t}$ and Work $\left._{s, t}\right)$, that are the weighted sum of the strength of the antismoking bans in bars, restaurants and workplaces attributed to each administrative territory. For example, the variable $\operatorname{Bar}_{s, t}$, which represents the average intensity of antismoking bans in bars in state $s$ at time $t$, can be written as

$$
\operatorname{Bar}_{s, t}=\sum_{a \in s} w_{a c s} \max \left\{\operatorname{Bar}_{a c s t}, \operatorname{Bar}_{c s t}, \operatorname{Bar}_{s t}\right\}
$$

where $w_{a c s}$ are weights based on the territory population, obtained from the 2010 U.S. Census. Hence Bar $_{s, t}$, Rest ${ }_{s, t}$ and $W_{o r k}, t$ represent the effective strength of the anti-smoking bans experienced by the average resident of state $s$ in day $t$ in each of these public places.

Figure 1 provides visual evidence of the trend in anti-smoking policies over the period 1999-2008. Two elements can be highlighted: first, there is general increase in the strengthening of all policies over the period; second, there is a considerable positive correlation between the implementation of different smoking bans. We control for this by identifying the effect of each policy simultaneously, by including state and time fixed effects, and by allowing for a state-specific time trend over the period of observation.

\section{Results}

In this Section, we report the results of model (1) for a set of dependent variables of eating behavior. Before doing so, and to check the consistency of our analysis with the existing literature, we study the effects of the antismoking policies under examination on the extensive and intensive margin of smoking. For comparability of the results, we consider the effects on smoking prevalence and on daily number of cigarettes smoked. The results are 
consistent with the literature. As shown in Table 3, an increase in tobacco excise taxes reduces the share of smokers in the population both in the short and in the medium term: a 10 cents raise in excise taxes reduces the share of smokers by $1 \%$ after one year, and by $1.5 \%$ in the second year after the enactment of the policy. The effect is mildly significant in the short term, while it becomes more precisely estimated in the medium term. Similarly to previous studies (Adda and Cornaglia, 2012), we fail to identify a significant effect of smoking bans in workplaces on smoking prevalence, while the effect of smoking bans in bars in the medium-term is negative, although it is only marginally significant.

The second column of Table 3 reports the results of estimating the effect of anti-smoking policies on the number of cigarettes smoked per day (i.e., the intensive margin) among the subsample of smokers. These results must be considered with caution, because focusing on those who are still smoking after the enactment of the policies is likely to yield a biased estimate of the true intensive margin of reduction. A better strategy would be to focus on those who were smokers right before the policy implementation, however the cross-sectional nature of NHANES prevents us to perform such exercise. With this caveat in mind, the results show that an increase in excise taxes is correlated with a reduction in the average number of cigarettes smoked in the state. A similar result is obtained by smoking bans in workplaces, while smoking bans in restaurants are correlated with an increase in the number of cigarettes smoked per day. The latter counterintuitive result may be due to the afore-mentioned sample selection generated by the policy itself: if it causes a reduction in smoking prevalence only among mild smokers, the share of heavy smokers in the count of smoking prevalence will increase. Since heavy smokers smoke a higher number of cigarettes per head, then the average number of cigarettes will increase.

\subsection{Effects on BMI and on quantity of food}

We start by replicating the exercise performed by Courtemanche, and estimate model (1) using log-BMI as the dependent variable. Results are provided in the first column of Table 4 . Consistently with his results, changes 
in tobacco excise taxes do not have a significant effect in the short term, while they do have a negative and significant effect after 2 years: a 10-cent increase in excise taxes decreases BMI by 2.4 percentage points (around 0.7 index points). Conversely, smoking bans do not have any significant effect on BMI.

A decrease in BMI (which is a stock variable) may be the result of a sufficiently strong reduction in the daily inflow of calories. ${ }^{6}$ Our dataset allows us to study in detail the food consumption flows, and to link them to the possible changes in body weight. The second column of Table 4 reports the results of regressing log-caloric intake using model (1). As expected, a two-year lag in excise taxes has a strong and negative effect: a 10-cent increase reduces caloric intakes by about 5.5\%. Conversely, the one-year lag coefficient is mildly significant and positive: this may signal that in the short-term individuals substitute food consumption for smoking, while in the longer term reducing smoking induces individual to eat less.

Although smoking bans do not affect BMI, they do impact on eating habit. By looking at measures of flows in food consumption we find that daily caloric intake increases after two years from the introduction of smoking bans in restaurants. This points the attention toward possible adjustments in individual habits (in particular, toward an increased attendance to restaurants) and, possibly, to the pricing policies by the restaurants, which we will discuss in the next sections.

When we look at total nutrients intake (measured in grams of food ingested daily), we obtain similar results for excise taxes and bans in restaurants. Considering smoking bans in bars, however, we observe a significant reduction, as a unit increase in the strength of the ban reduces total grams of food eaten by $14.26 \%$. Hence, individuals exposed to bans in bars reduce the amount of food eaten, while increasing the caloric content of it, and maintain constant their daily caloric intake. ${ }^{7}$

\footnotetext{
${ }^{6}$ Or by an increase in the consumption of calories (e.g., via physical exercise), we discuss this channel in Section 5.

${ }^{7}$ It is worth noticing that there is no clear consensus on the variable used by humans to peg their food needs. Some authors argue it is total nutrients intake (Rolls et al., 1998), some others consider caloric intake (Brunstrom and Rogers 2012), finally more
} 


\subsection{Effects on the quality of food}

Whether total food intake is maintained constant, increased, or decreased, individual's health also significantly depends on its quality (Kant 1996). We exploit NHANES food diaries and blood analyses to obtain direct measures of the effect of anti-smoking policies on the share of daily nutrients eaten over total food intake, and on the concentration of HDL cholesterol, LDL cholesterol, and triglycerides in the blood. Table 5 reports results for shares of different nutrients. The effect of an increase in excise taxes is markedly different in the short and in the medium run. During the first year after the tax increase, individuals experience an overall reduction in the quality of food eaten: the reduction in carbohydrates is accompanied by a significant increase in proteins and in all types of fats. Over the second year, however, the pattern is partially reversed, as the quality of food eaten is better than it was before the tax was raised: proteins get back to the initial level, and the share of carbohydrates increase. The share of fibers raises by $1.32 \%$ (which is more than half a standard deviation of the variable, see Table 1). Finally, fats are significantly reduced by $1.3 \%$ for every 10 cents increase in excise taxes.

Table 4 shows that the reduction in total nutrient intake after two years from the introduction of smoking bans in bars is mainly driven by a reduction in carbohydrates, proteins, and fibers. Thus, notwithstanding the lower total nutrient intake, some concerns on health may be raised for a worsening of the daily balance between nutrients. The effects of the bans in restaurants and workplaces, instead, are mainly in the first year and do not seem to last in the medium-long term. After two years since the strengthening of smoking bans in restaurants, only a mild reduction in the share of proteins can be appreciated, while bans in workplaces do not have any significant effect on the quality of food.

From blood analyses we obtain information on the concentration $(\mathrm{mg} / \mathrm{dL})$ of lipoproteins (cholesterols and triglycerides) in blood. Estimates of the ef-

recent researches show that individuals may peg their food needs on the basis of the daily protein intake (Weigle et al., 2005). 
fects of anti-smoking policies on these variables are reported in Table 6 . The positive effect of tobacco excise taxes on food quality is confirmed even by blood-level data: after two years from a 10-cent increase in taxes, LDL cholesterol drops by $4.4 \%$, while HDL increases by $2.8 \%$. Triglycerides concentration is reduced by $6 \%$. The negative impact of smoking bans in bars, as measured by shares of nutrients, is confirmed by blood-level analyses: after two years from the strengthening of the bans, LDL and triglycerides increase, while the "good" cholesterol is reduced. Finally, there is evidence of a positive effect of smoking bans in restaurants on HDL cholesterol.

\section{Discussion}

The results presented in the previous section allow us to show that tobacco taxes and smoking bans can produce very different results on eating behavior and body weight. Tobacco excise taxes induce a reduction of BMI, caloric intake and total nutrients. The reduction in the quantity of food is accompanied by an improvement in the quality of the diet, with a higher proportion of fibers and carbohydrates, and a lower proportion of fats. This improvement can be appreciated even from blood-analyses, which show a drop in LDL cholesterol and triglycerides and an increase in the concentration of HDL cholesterol.

Smoking bans in bars, instead, do not have a direct effect on BMI, but they slightly reduce the daily grams of nutrients intake. This small reduction is counterbalanced by the worse quality of the food, as the share of fats increases, and the concentration of LDL and triglycerides rises.

Finally, bans in restaurants induce individuals to eat larger amounts of food, both in terms of caloric intake and in terms of total nutrients. The composition of the diet is not significantly affected by this increase, with some evidence that HDL concentration rises. Bans in workplaces affect neither the quantity nor the quality of food eaten.

Which are the channels through which taxes and smoking bans affect food consumption? Although both policy interventions change the incentives to smoking, they act through different pathways. Excises taxes raise the mon- 
etary cost of each cigarette, irrespective of the place where the cigarette is smoked. In a static framework, we would expect the smoker to react by reducing the number of cigarettes and to increase food consumption. This is indeed what we observe in the first year after the increase in excises. Addiction to smoking, body weight, and eating habits, however, take time to change, and the correct theoretical framework to interpret the effect of a change in the price of cigarettes requires a dynamic framework. If increasing the taxes on tobacco only affects individual incentives of a smoker, the theoretical predictions presented by Dragone et al. (2012), who study the long-run price effects in a dynamic model where smoking is addictive and food consumption affects body weight, turn out to be useful. ${ }^{8}$ According to that model, the decrease in smoking, food consumption and body weight we reported after an increase in the price of smoking signals that smoking reinforces food consumption. When reinforcement is strong enough, a reduction in smoking due to an increase in the price of tobacco leads to a reduction in the total amount of food intake and in body weight. In other words, food and smoking are complements, so that the introduction of excise taxes on tobacco allows to address two different, but related targets such as the reduction in food consumption and body weight by using just a single policy tool. Given that discussing, designing and implementing a public policy aimed at improving health-related behavior is costly, this is clearly good news for the policy maker and for the tax-payer.

When considering the effect of bans on eating behavior, the picture becomes more complicated because bans do not affect the cost of each smoked cigarettes, but they are binding only in specific places and occasions. This may reduce the effectiveness of a ban in discouraging smoking behavior and the consequent effects on eating behavior, because the smoker can avoid the places where smoking is banned. The casual evidence of smokers gathering outside of restaurants or pubs where a smoking ban is enforced suggests an interesting effect produced by antismoking bans, where the "smoking break" becomes the occasion to socialize and chat with other smokers. If smokers

\footnotetext{
${ }^{8}$ It is clearly questionable whether our empirical estimates over a two-years horizon can be reasonably compared with theoretical predictions over an infinite time-horizon contained in Dragone et al. (2012). For our purposes, however, these predictions are useful to show a possible rationale for the observed empirical results.
} 
enjoy these occasions, the ban produces a benefit from smoking, an effect which goes in the opposite direction with respect to the intentions of the policy maker. Hence, it is not obvious to expect a smoking ban to unambiguously discourage smoking, which may explain why the empirical literature has often reported small or nil effects of this kind of policy interventions. An additional, but very relevant feature of smoking bans is that they directly address one of the main concerns of the policy makers: the fact that smokers create an externality on non-smokers. By creating non smoking areas, a ban changes the way in which both smokers and non-smokers enjoy public places. In this direction, we can provide evidence that smoking bans in bars and restaurants induce people to go more often in these public places. Table 8 provides results of the effect of anti-smoking policies on two goods that are largely consumed in US bars (caffeine and alcohol) and on the number of times that the individuals report to go to restaurants over a typical week. As it can be seen, after two years bans in bars induce a significant rise in both caffeine and alcohol consumption, ${ }^{9}$ while the introduction of a ban in restaurants increases the number of times that individuals eat out of home. This higher attendance may be explained by two reasons: it may be that a smoke-free restaurant or bar is perceived as an amenity by customers (either smokers, or non-smokers, or both); or it may be that in the long-run bars and restaurants have changed their pricing policies to counteract the potential loss of smoker customers. Although with our data we are not able to disentangle these two effects, the fact that smoking bans in restaurants and pubs have induced an increased demand for goods sold in restaurants and pubs deserves careful consideration by the policy maker. On one hand, although customers go more often to bars and restaurant after two years since the enactment of the bans, we record no increase in BMI. If one disposed of no additional information on dietary choices and on the medical condition of people, it would be tempting to conclude that bans are ineffective on changing eating behavior. This would be misleading, however, because we can see that smoking bans do impact on individual eating behavior, although the effects go in different directions. Customers of restaurants eat more healthy

\footnotetext{
${ }^{9}$ The same association is observed if we look at the concentration of alcohol and caffeine in blood.
} 
food, while customers of pubs eat slightly less than before the enactment of the ban, but the quality is worse.

One may wonder whether these changes in eating habits and weight are intentional or not. The NHANES contains information on interviews where people where asked to report their weight at the time of the interview and one year before it. ${ }^{10}$ This yields a subjective measure of perceived weight change over the year. If this weight change is larger than 10 pounds in absolute value, the person was also asked to report whether this change was intentional or not, and whether this goal was achieved by being on a diet and/or by exercising. The first column of Table 7 reports the results obtained by regressing the log-difference weight change during the year before the interview on anti-smoking policies. It is reassuring to observe that the estimate of the long-term effect of a tax increase is negative, as it was using objective measures of weight loss.

The second column of Table 7 provides the estimates of a linear probability model in which the dependent variable is a dummy equal to 1 if individuals have tried to intentionally lose weight. In the short term tobacco excise taxes reduce the intention to lose weight, while this intention increases over the longer term. Finally, in the last two columns we report the results of linear probability models in which the dependent variables take value 1 if the individual decided to reduce weight by being on diet or by exercising (the two answers are not mutually exclusive). The results show that the intentional weight loss due to an increase in taxes was obtained through dieting, and that the perceived weight gain that followed a strengthening of bans in bars induced individuals to exercise and to follow a stricter diet. ${ }^{11}$

\footnotetext{
${ }^{10}$ This subjective measure of weight was not used to calculate BMI, which we instead calculated from the objective measurements of weight and height performed by the CDC personnel.

${ }^{11}$ Interestingly people report having increased their body weight, a result that is not consistent with the objective measures based on BMI. The perceived increase in weight reported after two years since bans in bars were strengthened does not seem to be intentional, while smoking bans in restaurants reduce the willingness to lose weight.
} 


\section{Conclusions}

In this paper we have provided new evidence on the effect of anti-smoking policies on food consumption. Our analysis extends the literature in two main directions. First, we consider the effect of antismoking policies on both stock variables, such as BMI, and on flow variables related to the quality and quantity of food. Second, we consider and compare a variety of antismoking policies such as excise taxes on tobacco and smoking bans in bars, restaurants and working places. This allows to disentangle the differential effect of each policy on individual body weight, and to precisely link these effects to changes in individual eating behavior and health.

We find that, after two years since their enactment, excise taxes reduce BMI and the quantity of consumed food. At the same time, the quality of the diet improves, with less fats, more carbohydrates, and fibers. This improvement can be appreciated even from blood analyses, where a reduction in LDL cholesterol and triglycerides and an increase in HDL cholesterol are observed. There is strong evidence that changes in eating habits are intentionally pursued by individuals.

Smoking bans have different effects on quantity and quality of food eaten: after bans in bars are introduced the quality of food becomes worse; as an effect of bans in restaurants, instead, the quantity of food consumed increases, although the quality slightly increases. We provide evidence suggesting that these effects may be driven by individuals going more often to bars and restaurants as a result of the strengthening of smoke-free laws. In particular, smoking bans in bars and restaurants would favour eating and drinking out. This increase in attendance of bars and restaurants may be explained by two non-competing reasons: first, it may be that a smoke-free public place has a higher perceived amenity value for individuals (including non-smokers); second, bars and restaurants may reduce their prices as a response to the smoking bans and to avoid losing customers. To gauge the role of these two different reasons, additional information on pricing policies implemented by bars and restaurants is needed. In addition, it would be interesting to identify whether this effect is relevant for smokers and non-smokers alike. However, the cross-sectional structure of the NHANES prevents us to distinguish the 
impact of the policies by smoking status.

While our results are in line with those authors suggesting that policymakers should not fear anti-smoking policies to increase BMI (e.g. Courtemanche, 2009; Wehby and Courtemanche, 2012), we suggest that we should still be cautionary in assessing the impact of antismoking policies on eating behaviors. Our main result is that antismoking policies substantially change the qualitative features of a person's diet. This association might enhance or impair the effectiveness of other weight-related policies. Identifying the channels and the effects of smoking on specific foods is thus still an open challenge that could potentially provide valuable results in terms of policy making. 


\section{References}

Abrevaya, J., Puzzello, L. (2012). Taxes, Cigarette Consumption. The American Economic Review, 102(4), 1751-1763.

Adda, J., Cornaglia, F. (2012). Taxes, cigarette consumption, and smoking intensity: reply. CEP Discussion Papers No 1167.

Adda, J., Cornaglia, F. (2010). The effect of bans and taxes on passive smoking. American Economic Journal: Applied Economics, 2(1), 1-32.

Adda, J., Cornaglia, F. (2006). Cigarette consumption and smoking intensity. The American Economic Review, 96(4), 1013-1028.

Baum, C. L. (2009). The effects of cigarette costs on BMI and obesity. Health Economics, 18(1), 3-19.

Brunstrom, J.M. and P.J. Rogers (2012). How Many Calories Are on Our Plate? Expected Fullness, Not Liking, Determines Meal-size Selection. Obesity, 17 (10), 1884-1890.

Burkhauser, R. V., Cawley, J. (2008). Beyond BMI: The value of more accurate measures of fatness and obesity in social science research. The Journal of Health Economics 27, 519-529.

Centers for Disease Control and Prevention (CDC), National Center for Health Statistics (NCHS), (1998-2008). National Health and Nutrition Examination Survey Data. Hyattsville, MD: U.S. Department of Health and Human Services, Centers for Disease Control and Prevention.

Chou, S., Grossman, M., Saffer, H. (2004). An economic analysis of adult obesity: results from the Behavioral Risk Factor Surveillance System. Journal of Health Economics, 23, 565-587.

Courtemanche, C. (2009) Rising cigarette prices and rising obesity: Coincidence or unintended consequence? Journal of Health Economics, 28, 781-798.

Dragone, D., Manaresi, F., Savorelli, L. (2012). Multiple rational addiction and the effect of price on consumption. Discussion paper FarmaFactoring Foundation.

Gruber, J., Frakes, M. (2006). Does falling smoking lead to rising obesity? Journal of Health Economics, 25, 183-197.

Kant, A.K. (1996). Indexes of Overall Diet Quality: a Review. Journal 
of the American Dietetic Association, 96(8), 785-791.

Liu, F., Zhang, N., Cheng, K.W., Wang, H. (2010). Reduced smoking and rising obesity: Does smoking ban in the workplace matter? Economics Letters, 108(3), 249-252.

Nonnemaker, J., Finkelstein, E., Engelen, M., Hoerger, T., Farrelly, M. (2009). Have efforts to reduce smoking really contributed to the obesity epidemic. Economic Inquiry, 47, 366-376.

Orzechowski,W.,Walker, R. (2011). The Tax Burden on Tobacco, Historical Compilation, vol. 40. Arlington, Virginia.

Prentice, A.M., Jebb, S.A. (2001). Beyond body mass index. Obesity Reviews 2 (3), 141-147.

Rashad, I., Grossman, M. (2004). The economics of obesity. Public Interest, 156, 104-112.

Rashad, I., Grossman, M., Chou, S. (2006). The super size of America: An economic estimation of body mass index and obesity in adults. Eastern Economic Journal, 32, 133-148.

Rolls, B., V. Castellanos, J. Halford, A. Kilara, D. Panyam, C. Pelkman, G. Smith, and M. Thorwart (1998) Volume of Food Consumed Affects Satiety in Men. American Journal of Clinical Nutrition, 67 (6), 1170-1177.

Sweanor, D. T., Martial, L. R. (1994) The Smuggling of Tobacco Products: Lessons from Canada. Ottawa (Canada): Non-Smokers' Rights Association/Smoking and Health Action Foundation.

Wehby, G. L., Courtemanche, C. J. (2012). The heterogeneity of the cigarette price effect on the body mass index. Journal of Health Economics, 31, 719-729.

Weigle, D.S., P.A. Breene, C.C. Matthys, et al. (2005). A high-protein diet induces sustained reductions in appetite, ad libitum caloric intake, and body weight despite compensatory changes in diurnal plasma leptin andghrelin concentrations. American Journal of Clinical Nutrition; 82, 41-48. 


\section{Tables and Figures}

Table 1: Descriptive statistics. Adult population, age 21 or older. Years $1999-2008$.

\begin{tabular}{l|ccc}
\hline \hline Variable & Mean & St.Dev. & No. of Obs. \\
\hline Body-Mass Index & 28.31 & 6.49 & 23846 \\
Daily KCalories & 2206.35 & 1035.19 & 23242 \\
Daily Nutrients (gm) & 450.39 & 203.69 & 23242 \\
& 3.32 & 0.22 & 23846 \\
& 7.59 & 0.48 & 23242 \\
Share of Carbohydrates & 6.01 & 0.46 & 23242 \\
Share of Proteine & 0.59 & 0.10 & 23242 \\
Share of Fibers & 0.19 & 0.06 & 23242 \\
Share of Total Fats & 0.04 & 0.02 & 23242 \\
Share of Saturated Fats & 0.18 & 0.06 & 23242 \\
Share of Polyunsaturated Fats & 0.06 & 0.02 & 23242 \\
Share of Monounsaturated Fats & 0.06 & 0.02 & 23242 \\
LDL-Cholesterol (mg/dL) & 0.07 & 0.03 & 23242 \\
HDL-Cholesterol (mg/dL) & 118.15 & 35.54 & 8663 \\
Triglycerides (mg/dL) & 52.82 & 16.01 & 18731 \\
Male & 153.74 & 125.49 & 16159 \\
Age & 0.48 & 0.50 & 27048 \\
College Education or Higher & 46.14 & 15.89 & 23444 \\
Mexican & 0.55 & 0.50 & 27048 \\
Black & 0.33 & 0.47 & 27048 \\
Other Ethnicities & 0.11 & 0.31 & 27048 \\
HH Size & 0.11 & 0.31 & 27048 \\
HH Head Male & 3.01 & 1.53 & 27048 \\
HH Head Age & 0.59 & 0.49 & 27043 \\
Ratio of Family Income to Poverty & 48.14 & 16.40 & 27043 \\
\hline \hline
\end{tabular}

Table 2: Weight classes and shares of smokers, weighted results.Adult population, age 21 or older. Years 1999 - 2008.

\begin{tabular}{|r|r|r|r|r|}
\hline Weight class & Obese & Overweight & Normal & Underweight \\
\hline Smoking prevalence (\%) & 20.6 & 22.0 & 28.7 & 42.1 \\
\hline Weight class share (\%) & 32.3 & 34.3 & 31.6 & 1.8 \\
\hline
\end{tabular}


Table 3: Effect of anti-smoking policies on smoking prevalence and number of cigarettes smoked (conditional on being a smoker). Years 1999-2008.

\begin{tabular}{lcc}
\hline \hline & Pr(Smoking) & No. of Cigarettes \\
per Day & -0.0535 \\
Excise Tax (unit USD) - year 1 & -0.101 & $(0.0250)^{* *}$ \\
Excise Tax (unit USD) - year 2 & $(0.060)^{*}$ & -0.0111 \\
Excise Tax Squared - year 1 & -0.1541 & $(0.0444)$ \\
& $(0.09401)^{*}$ & 0.20 \\
Excise Tax Squared - year 2 & 0.05 & $(0.10)^{*}$ \\
Bans in Bars - Year 1 & $(0.025)^{* *}$ & 0.00 \\
Bans in Bars - Year 2 & 0.07 & $(0.20)$ \\
Bans in Restaurants - Year 1 & $(0.040)$ & 0.4497 \\
Bans in Restaurants - Year 2 & $(0.0149$ & $(0.5849)$ \\
Bans in Working Places - Year 1 & -0.0334 & 0.6434 \\
Bans in Working Places - Year 2 & $(0.0175)^{*}$ & -3.342 \\
Time FE & -0.0533 & $(2.0294)$ \\
State-spec. trend & $(0.0527)$ & 4.7305 \\
Obs. & 0.0503 & $(1.8643)^{* *}$ \\
\hline \hline
\end{tabular}

Notes: Standard errors are clustered at the state level. Controls include gender, age, education, and ethnicity of the interviewed person; household size, household income (measured as the distance from the poverty line), household head gender and age, and a set of day of the week dummies. $* * *$ indicates statistically significant at $1 \%$ level; ** at $5 \%$ level; * at $10 \%$ level. 
Table 4: Effect of anti-smoking policies on (log) BMI, (log) daily KCal, (log) daily total nutrients. Years 1999-2008.

\begin{tabular}{lccc}
\hline \hline & log-BMI & log-KCal & log-Total Nutrients \\
Excise Tax (unit USD) - year 1 & -0.0786 & 0.305 & 0.1771 \\
Excise Tax (unit USD) - year 2 & $(0.1308)$ & $(0.1764)^{*}$ & $(0.1630)$ \\
Excise Tax Squared - year 1 & -0.2542 & -0.590 & -0.5434 \\
& $(0.07933)^{* * *}$ & $(0.1288)^{* * *}$ & $(0.1360)^{* * *}$ \\
Excise Tax Squared - year 2 & -0.00 & -0.10 & -0.04 \\
Bans in Bars - Year 1 & $(0.052)$ & $(0.067)$ & $(0.10)$ \\
& 0.130 & 0.40 & 0.340 \\
Bans in Bars - Year 2 & $0.040)^{* * *}$ & $(0.40)^{* * *}$ & $(0.10)^{* * *}$ \\
Bans in Restaurants - Year 1 & 0.0306 & -0.0003 & 0.0225 \\
Bans in Restaurants - Year 2 & $(0.0284)$ & $(0.03775)$ & $(0.0348)$ \\
Bans in Working Places - Year 1 & 0.0546 & 0.03775 & -0.1426 \\
Bans in Working Places - Year 2 & $(0.03628)$ & $(0.03736)$ & $(0.0389)^{* * *}$ \\
& -0.1028 & 0.0853 & 0.0733 \\
Controls & $(0.0949)$ & $(0.1070)$ & $(0.1270)$ \\
State FE & 0.0449 & 0.4761 & 0.5831 \\
Time FE & $(0.2340)$ & $(0.2000)^{* *}$ & $(0.2172)^{* *}$ \\
State-spec. trend & $(0.1751$ & -0.1842 & -0.1898 \\
Obs. & $\mathrm{Y}$ & $(0.1059)$ & $(0.1312)$ \\
\hline \hline
\end{tabular}

Notes: Standard errors are clustered at the state level. Controls include gender, age, education, and ethnicity of the interviewed person; household size, household income (measured as the distance from the poverty line), household head gender and age, and a set of day of the week dummies. ${ }^{* * *}$ indicates statistically significant at $1 \%$ level; $* *$ at $5 \%$ level; $*$ at $10 \%$ level. 
Table 5: Effect of anti-smoking policies on $(\log )$ shares of nutrients. Years 1999-2008.

\begin{tabular}{|c|c|c|c|c|c|c|c|}
\hline & \multicolumn{7}{|c|}{ Shares of Nutrients } \\
\hline & Carbohydrates & Proteins & Fibers & Fats & Saturated & Polyunsat. & Monounsat. \\
\hline Excise Tax (unit USD) - Year 1 & $\begin{array}{l}-0.1760 \\
(0.0399)^{* * *}\end{array}$ & $\begin{array}{l}0.0622 \\
(0.0261)^{* *}\end{array}$ & $\begin{array}{c}0.0086 \\
(0.0076)\end{array}$ & $\begin{array}{l}0.1052 \\
(0.0225) * * *\end{array}$ & $\begin{array}{l}0.0369 \\
(0.0101)^{* * *}\end{array}$ & $\begin{array}{l}0.0230 \\
(0.0070)^{* * *}\end{array}$ & $\begin{array}{c}0.0453 \\
(0.0115)^{* * * *}\end{array}$ \\
\hline Excise Tax (unit USD) - Year 2 & $\begin{array}{l}0.1308 \\
(0.0427)^{* * *}\end{array}$ & $\begin{array}{l}-0.0153 \\
(0.0318)\end{array}$ & $\begin{array}{c}0.0137 \\
(0.0074)^{*}\end{array}$ & $\begin{array}{l}-0.1293 \\
(0.0190)^{* * *}\end{array}$ & $\begin{array}{l}-0.0413 \\
(0.0076)^{* * *}\end{array}$ & $\begin{array}{l}-0.0321 \\
(0.0058)^{* *}\end{array}$ & $\begin{array}{l}-0.0558 \\
(0.0091)^{* * *}\end{array}$ \\
\hline Excise Tax Squared - Year 1 & $\begin{array}{l}0.0500 \\
(0.0200)^{* * *}\end{array}$ & $\begin{array}{l}-0.0002 \\
(0.0001)\end{array}$ & $\begin{array}{c}0.0010 \\
(0.0030)\end{array}$ & $\begin{array}{l}-0.0340 \\
(0.0100)^{* * *}\end{array}$ & $\begin{array}{l}-0.0110 \\
(-0.0050) * * *\end{array}$ & $\begin{array}{l}-0.0090 \\
(0.0031)^{* * *}\end{array}$ & $\begin{array}{l}-0.0150 \\
(0.0050)^{* * *}\end{array}$ \\
\hline Excise Tax Squared - Year 2 & $\begin{array}{l}-5.7000 \\
(0.0200)^{* * *}\end{array}$ & $\begin{array}{l}0.0001 \\
(0.0001)\end{array}$ & $\begin{array}{l}-0.0050 \\
(0.0040)\end{array}$ & $\begin{array}{l}0.0056 \\
(0.0100)^{* * *}\end{array}$ & $\begin{array}{l}0.0170 \\
(0.0044)^{* * *}\end{array}$ & $\begin{array}{l}0.0140 \\
(0.0038)^{* * *}\end{array}$ & $\begin{array}{l}0.0250 \\
(0.0060)^{* * *}\end{array}$ \\
\hline Bans in Bars - Year 1 & $\begin{array}{l}-0.0006 \\
(0.0099)\end{array}$ & $\begin{array}{l}-0.0023 \\
(0.0055)\end{array}$ & $\begin{array}{c}0.0004 \\
(0.0012)\end{array}$ & $\begin{array}{l}0.0024 \\
(0.0050)\end{array}$ & $\begin{array}{l}0.0004 \\
(0.0024)\end{array}$ & $\begin{array}{l}0.1076 \\
(0.2031)\end{array}$ & $\begin{array}{l}0.0965 \\
(0.2451)\end{array}$ \\
\hline Bans in Bars - Year 2 & $\begin{array}{l}-0.0307 \\
(0.0525)^{* * *}\end{array}$ & $\begin{array}{l}0.0119 \\
(0.0080)\end{array}$ & $\begin{array}{l}-0.0058 \\
(0.0010)^{* * *}\end{array}$ & $\begin{array}{l}0.0246 \\
(0.0054)^{* * *}\end{array}$ & $\begin{array}{l}0.0095 \\
(0.0027)^{* * *}\end{array}$ & $\begin{array}{l}0.7155 \\
(0.2001)^{* * *}\end{array}$ & $\begin{array}{l}0.7909 \\
(0.2398)^{* * *}\end{array}$ \\
\hline Bans in Restaurants - Year 1 & $\begin{array}{l}-0.0593 \\
(0.0299)^{*}\end{array}$ & $\begin{array}{l}0.0469 \\
(0.0179)^{* * *}\end{array}$ & $\begin{array}{c}0.0093 \\
(0.0049)^{*}\end{array}$ & $\begin{array}{l}0.0031 \\
(0.0158)\end{array}$ & $\begin{array}{l}0.0042 \\
(0.0048)\end{array}$ & $\begin{array}{l}-0.0028 \\
(0.0073)\end{array}$ & $\begin{array}{l}0.0017 \\
(0.0071)\end{array}$ \\
\hline Bans in Restaurants - Year 2 & $\begin{array}{l}0.0601 \\
(0.0479)\end{array}$ & $\begin{array}{l}-0.0556 \\
(0.0286)^{* *}\end{array}$ & $\begin{array}{l}-0.0023 \\
(0.0091)\end{array}$ & $\begin{array}{l}-0.0022 \\
(0.0290)\end{array}$ & $\begin{array}{l}-0.0028 \\
(0.0115)\end{array}$ & $\begin{array}{c}0.0000 \\
(0.0150)\end{array}$ & $\begin{array}{l}0.0005 \\
(0.0130)\end{array}$ \\
\hline Bans in Working Places - Year 1 & $\begin{array}{l}0.0493 \\
(0.0318)\end{array}$ & $\begin{array}{l}-0.0378 \\
(0.0194)^{* *}\end{array}$ & $\begin{array}{l}-0.0155 \\
(0.0051)^{*}\end{array}$ & $\begin{array}{l}0.0040 \\
(0.0171)^{*}\end{array}$ & $\begin{array}{l}-0.0026 \\
(0.0048)\end{array}$ & $\begin{array}{c}0.0058 \\
(0.0080)\end{array}$ & $\begin{array}{l}0.0008 \\
(0.0078)\end{array}$ \\
\hline Bans in Working Places - Year 2 & $\begin{array}{l}-0.0362 \\
(0.0525)\end{array}$ & $\begin{array}{l}0.0403 \\
(0.0308)\end{array}$ & $\begin{array}{c}0.0096 \\
(0.0103)\end{array}$ & $\begin{array}{l}-0.0138 \\
(0.0328)\end{array}$ & $\begin{array}{l}0.0001 \\
(0.0117)\end{array}$ & $\begin{array}{l}-0.007 \\
(0.01681)\end{array}$ & $\begin{array}{l}-0.006 \\
(0.0145)\end{array}$ \\
\hline Controls & $\mathrm{Y}$ & $\mathrm{Y}$ & $\mathrm{Y}$ & $\mathrm{Y}$ & $\mathrm{Y}$ & $\mathrm{Y}$ & $\mathrm{Y}$ \\
\hline State FE & $\mathrm{Y}$ & $\mathrm{Y}$ & $\mathrm{Y}$ & $\mathrm{Y}$ & $\mathrm{Y}$ & $\mathrm{Y}$ & $\mathrm{Y}$ \\
\hline Time FE & $\mathrm{Y}$ & $\mathrm{Y}$ & $\mathrm{Y}$ & $\mathrm{Y}$ & $\mathrm{Y}$ & $\mathrm{Y}$ & $\mathrm{Y}$ \\
\hline State-spec. trend & $\mathrm{Y}$ & $\mathrm{Y}$ & $\mathrm{Y}$ & $\mathrm{Y}$ & $\mathrm{Y}$ & $\mathrm{Y}$ & Y \\
\hline Obs. & 16359 & 16359 & 16359 & 16359 & 16359 & 16359 & 16359 \\
\hline
\end{tabular}

Notes: Standard errors are clustered at the state level. Controls include gender, age, education, and ethnicity of the interviewed person; household size, household income (measured as the distance from the poverty line), household head gender and age, and a set of day of the week dummies.*** indicates statistically significant at $1 \%$ level; ${ }^{* *}$ at $5 \%$ level; * at $10 \%$ level. 
Table 6: Effect of anti-smoking policies on $(\log )$ LDL, (log) HDL cholesterol, (log) triglycerids. Years 1999-2008.

\begin{tabular}{lllll}
\hline \hline & \multicolumn{2}{c}{ Cholesterol } & \multirow{2}{*}{ Triglycerides } \\
\cline { 1 - 3 } Excise Tax (unit USD) - Year 1 & 0.1690 & 0.0237 & -0.0730 \\
& $(0.2012)$ & $(0.0939)$ & $(0.1475)$ \\
Excise Tax (unit USD) - Year 2 & -0.4520 & 0.2967 & -0.6190 \\
& $(0.1553)^{* * *}$ & $(0.1379)^{* *}$ & $(0.3653)^{*}$ \\
Excise Tax Squared - Year 1 & -0.1000 & -0.0500 & 0.1000 \\
& $(0.0780)^{*}$ & $(0.0400)$ & $(0.0710)^{* *}$ \\
Excise Tax Squared - Year 2 & 0.1000 & -0.1800 & 0.6000 \\
& $(0.1140)$ & $(0.0800)^{* *}$ & $(0.2140)^{* * *}$ \\
Bans in Bars - Year 1 & -0.0081 & 0.0866 & -0.2197 \\
& $(0.0388)$ & $(0.0247)^{* * *}$ & $(0.0737)^{* * *}$ \\
Bans in Bars - Year 2 & 0.1089 & -0.0695 & 0.1408 \\
& $(0.0400)^{* * *}$ & $(0.0315)^{* *}$ & $(0.0770)^{*}$ \\
Bans in Restaurants - Year 1 & 0.4389 & -0.1419 & 0.1143 \\
& $(0.1304)^{* * *}$ & $(0.0922)$ & $(0.1862)$ \\
Bans in Restaurants - Year 2 & -0.1088 & 0.3709 & -0.2858 \\
& $(0.2462)$ & $(0.1693)^{* *}$ & $(0.3475)$ \\
Bans in Working Places - Year 1 & -0.2059 & 0.0755 & -0.1307 \\
& $(0.1446)$ & $(0.1043)$ & $(0.2062)$ \\
Bans in Working Places - Year 2 & -0.1726 & -0.3251 & 0.2720 \\
& $(0.2813)$ & $(0.1941)$ & $(0.3798)$ \\
\hline Obs. & 16359 & 16359 & 16359 \\
\hline \hline
\end{tabular}

Notes: Standard errors are clustered at the state level. Controls include gender, age, education, and ethnicity of the interviewed person; household size, household income (measured as the distance from the poverty line), household head gender and age, and a set of day of the week dummies. *** indicates statistically significant at $1 \%$ level; ${ }^{* *}$ at $5 \%$ level; * at $10 \%$ level. 
Table 7: Effect of anti-smoking policies on (log) reduction in weight and (log) probability of having an intentional weight change (conditional on weight loss), number of times at the restaurant per week (non-log), decision to control weight, and two methods of weight control: exercising (exercised), reducing the amount of consumed calories (lower_cal). Years 1999-2008.

\begin{tabular}{lllll}
\hline \hline & Weight Loss & Intentional & Exercise & Diet \\
\hline Excise Tax (unit USD) - Year 1 & 2.5130 & -1.4930 & 0.3960 & 0.3280 \\
& $(1.9186)$ & $(0.0028)^{* * *}$ & $(0.1560)^{* *}$ & $(0.1530)^{* *}$ \\
Excise Tax (unit USD) - Year 2 & -4.1660 & 1.4870 & 0.3050 & 0.2270 \\
& $(1.8700)^{* *}$ & $(0.4078)^{* * *}$ & $(0.1970)$ & $(0.1150)^{* *}$ \\
Excise Tax Squared - Year 1 & -0.7000 & 0.4000 & -0.0000 & -0.0000 \\
& $(0.6500)$ & $(0.1150)^{* * *}$ & $(0.1000)$ & $(0.1000)$ \\
Excise Tax Squared - Year 2 & 1.8000 & -0.5000 & -0.1000 & -0.0000 \\
& $(1.26)$ & $(0.2110)$ & $(0.1000)$ & $(0.1000)$ \\
Bans in Bars - Year 1 & -0.2705 & -0.2407 & -0.1196 & -0.9500 \\
& $(0.4726)$ & $(0.0744)^{* * *}$ & $(0.0420)^{* * *}$ & $(3.181)$ \\
Bans in Bars - Year 2 & 1.5949 & 0.1767 & 0.2880 & 6.7500 \\
& $(0.4893)^{* *}$ & $(0.0911)$ & $(0.0392)^{* * *}$ & $(3.4490)^{* *}$ \\
Bans in Restaurants - Year 1 & 0.4389 & -0.3002 & 0.3909 & 5.0900 \\
& $(1.5169)$ & $(0.2429)$ & $(0.1388)^{* * *}$ & $(10.9470)$ \\
Bans in Restaurants - Year 2 & -4.3228 & -1.0590 & -0.3088 & -12.0100 \\
& $(3.0729)$ & $(0.3553)^{* * *}$ & $(0.2921)$ & $(21.3600)$ \\
Bans in Working Places - Year 1 & -1.5600 & 0.5465 & -0.2646 & -11.3600 \\
& $(1.7030)$ & $(0.2425)^{* *}$ & $(0.1550)^{*}$ & $(12.7410)$ \\
Bans in Working Places - Year 2 & 2.2469 & 0.9250 & -0.0282 & 13.4600 \\
& $(3.412)$ & $(0.3466)^{* *}$ & $(0.3119)$ & $(23.3860)$ \\
\hline Obs. & 16359 & 16359 & 17155 & 17155 \\
\hline \hline
\end{tabular}

Notes: Standard errors are clustered at the state level. Controls include gender, age, education, and ethnicity of the interviewed person; household size, household income (measured as the distance from the poverty line), household head gender and age, and a set of day of the week dummies.*** indicates statistically significant at $1 \%$ level; ${ }^{* *}$ at $5 \%$ level; ${ }^{*}$ at $10 \%$ level. 
Table 8: Effect of anti-smoking policies on $(\log )$ alcohol and $(\log )$ caffeine in blood analysis. Years 1999-2008.

\begin{tabular}{llll}
\hline \hline & $(\log )$ Caffeine & $(\log )$ Alcohol & Rest. per week \\
\hline Excise Tax (unit USD) - Year 1 & -2.9849 & 6.8600 & -21.2800 \\
& $(1.5200)^{*}$ & $(2.4652)^{* * *}$ & $(23.9900)$ \\
Excise Tax (unit USD) - Year 2 & -1.4233 & 5.4300 & -48.5600 \\
& $(1.4500)$ & $(1.7650)^{* * *}$ & $(26.7800)^{*}$ \\
Excise Tax Squared - Year 1 & 0.0173 & -0.0200 & 11.0000 \\
Excise Tax Squared - Year 2 & $(0.0100)$ & $(0.0083)^{* *}$ & $(14.0000)$ \\
& 0.0086 & -0.0200 & 35.0000 \\
Bans in Bars - Year 1 & $(0.0001)^{* *}$ & $(0.0119)$ & $(21.0000)$ \\
& -0.8979 & -0.4814 & 22.1539 \\
Bans in Bars - Year 2 & $(0.2035)^{* * *}$ & $(0.4305)$ & $(29.2080)$ \\
Bans in Restaurants - Year 1 & 0.6965 & 1.6978 & -2.1811 \\
Bans in Restaurants - Year 2 & $(0.3221)^{* *}$ & $(0.5175)^{* * *}$ & $(1.0300)^{* *}$ \\
& 0.0178 & 0.9325 & -28.2085 \\
Bans in Working Places - Year 1 & $(0.9022)$ & $(2.0106)$ & $(15.4556)^{*}$ \\
Bans in Working Places - Year 2 & 0.1978 & 0.5473 & 14.6050 \\
& $(1.5345)$ & $(3.7087)$ & $(5.5489)^{* * *}$ \\
\hline Obs. & 0.4544 & -1.4716 & -45.4199 \\
\hline \hline
\end{tabular}

Notes: Standard errors are clustered at the state level. Controls include gender, age, education, and ethnicity of the interviewed person; household size, household income (measured as the distance from the poverty line), household head gender and age, and a set of day of the week dummies. *** indicates statistically significant at $1 \%$ level; $* *$ at $5 \%$ level; $*$ at $10 \%$ level. 


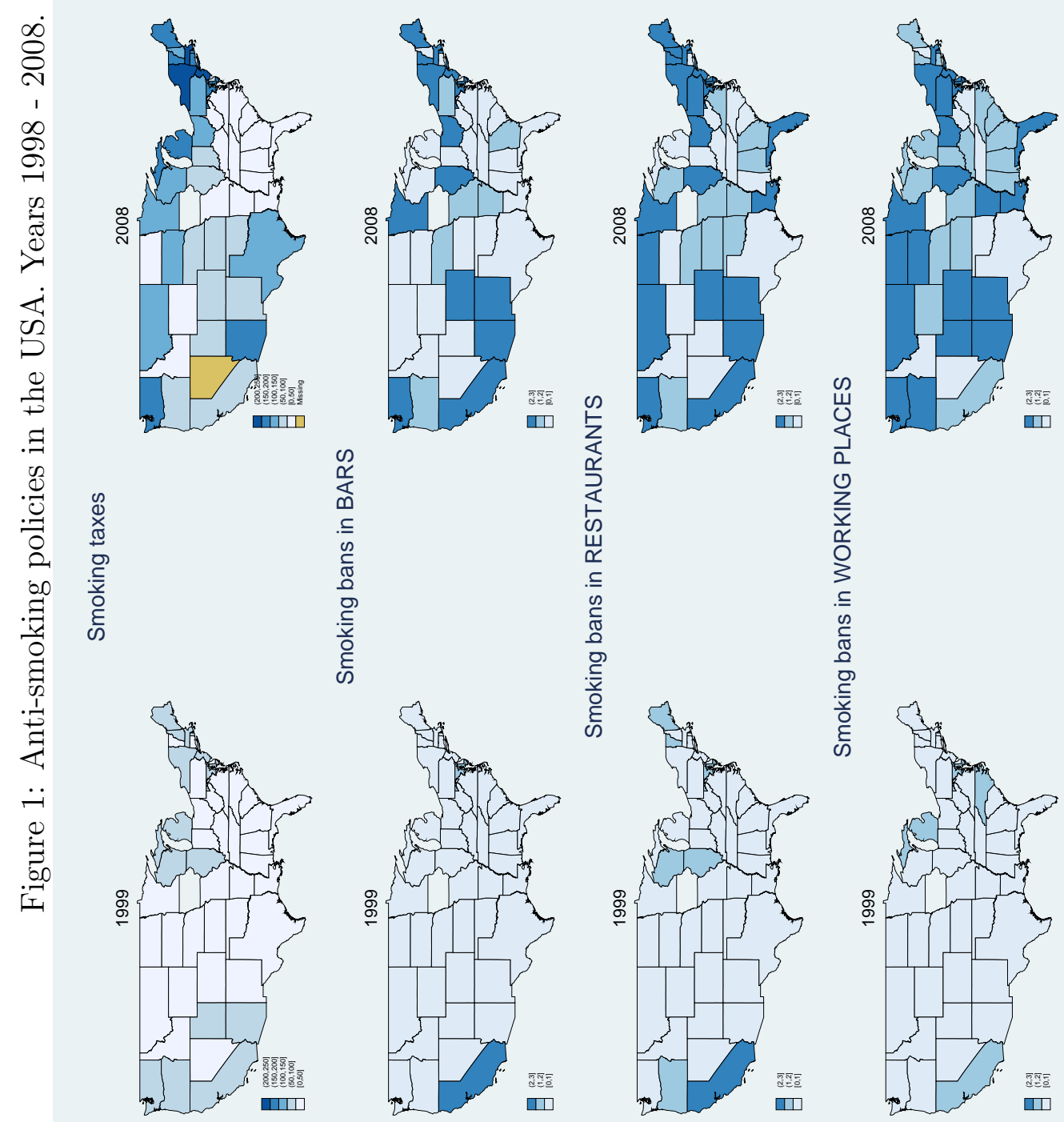




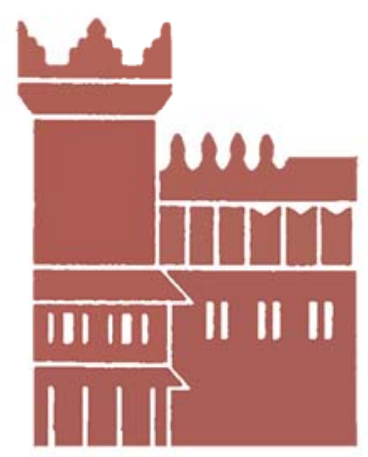

Alma Mater Studiorum - Università di Bologna DEPARTMENT OF ECONOMICS

Strada Maggiore 45

40125 Bologna - Italy

Tel. +39051 2092604

Fax +390512092664

http://www.dse.unibo.it 